\title{
Retos y desafíos de la res publica en la obra historiográfica de Salustio. Las emociones políticas en la vida pública*
}

\author{
Challenges and threats to \\ res publica in Sallust' work. \\ Political emotions in public life
}

\begin{abstract}
Resumen: El artículo pretende caracterizar el proyecto histórico-literario emprendido por Salustio tras su retiro de la vida pública. Asimismo, el autor de este artículo se propone rastrear las ideas vertebradoras de la antropología política subyacente a la obra del historiador latino. Se presentará La Conjuración de Catilina y La Guerra de Jugurta como dos obras en las que se muestran algunos de los principales retos y desafíos que deben ser afrontados por cualquier sistema político aspirante a ser res publica. Retos que son productos del peculiar fondo emocional antropológico del que surgen los desequilibrios que mueven al hombre.
\end{abstract}

Palabras clave: Proyecto Historiográfico, Res Publica, Antropología Política, Pasiones Políticas, Retos Políticos.

JUAN CARLOS BARRASÚS HERRERO**

\begin{abstract}
The article aims to characterise the historical and literary project undertaken by Sallust after his retirement from public life. It will also be attempted to identify the political anthropology underlying Sallust' work. The conspiracy of Catiline and Jugurthine War are to be presented as a catalogue of some of the main risks and threats which must be faced by any political system resolved to be or to become res publica. Threats and risks which arise from the peculiar and emotional anthropological depths from which human instability and movement take place.
\end{abstract}

Keywords: Historiographical Project, Res Publica, Political Anthropology, Political Passions, Political Threats.

Fecha de recepción: 10/06/2016. Fecha de aceptación: 06/09/2016.

* Este artículo ha sido escrito en el contexto del Proyecto de Investigación "Las Retóricas del Clasicismo. Los puntos de vista (contextos, premisas, mentalidades)" FFI2013-41410-P financiado por el MINECO y cuyo Investigador Principal es Juan Luis Conde.

** Doctorando en filosofía en la Universidad Complutense de Madrid. E-mail: jc.barrasus@googlemail.com. Escribe una tesis doctoral sobre Tácito y la historiografía romana. Junto con Juan Luis Conde (UCM) y como editor ha publicado en 2015 el número Tácito: el poder y su retratista en la revista Hybris (Especial Vol. 6). Como autor ha publicado «¿Qué hacer tras la catástrofe? El problema del "reencantamiento del mundo" y la primacía de lo ético en el itinerario intelectual de Hermann Broch» en Hannah Arendt y la literatura (Bellaterra, 2016) número editado por Nuria Sánchez Madrid (UCM). 


\section{El proyecto historiográfico de Salustio: retiro de la vida pública, retrato de la deca- dencia de Roma, búsqueda de la inmortalidad literaria}

La obra histórico-literaria ${ }^{1}$ de Gayo Salustio Crispo $^{2}$ aparece ante los ojos del lector como un compendio de escritos monográficos -Guerra de Jugurta, Conjuración de Catilina- así como un proyecto de historia general de Roma que debía dar cuenta de los sucesos políticos ocurridos entre el año 78 y el año 67 a. C. (SANTOS YANGUAS, 1997, 42). En dicha obra es posible rastrear con relativa facilidad la antropología política subyacente a dichas narraciones. Por una parte, aparecen escasas aunque jugosas y perspicaces observaciones y digresiones acerca de los rasgos más característicos y diferenciales de la condición humana ${ }^{3}$. Por otra parte, podemos encontrar algo así como un «catálogo» desordenado e incompleto de los principales retos y riesgos a los que deberá enfrentarse todo sistema político humano aspirante a ser de alguna manera res publica.

Tal parece ser el proyecto intelectual que el historiador latino tiene en mente cuando selecciona como materiales narrativos de sus escritos aquellos sucesos, acontecimientos y personajes de singular relevancia y de naturaleza arquetípica -tanto de la historia de la Roma más remota como de la historia más cercana a la existencia de Salustio - dignos de ser recordados por la posteridad gracias al talento y al buen hacer del historiador. El resultado de la combinación del vasto conocimiento del pasado de Roma atesorado por Salustio con la fértil imaginación del escritor romano permiten al autor de estos relatos componer relatos hondos y significativos, educativos y moralizantes dirigidos a todos aquellos hombres cultos a la par que ociosos deseosos de ver desfilar a lo largo de las páginas de la narración lo más característico del «teatro del mundo político» en una narración histórica. O dirigidos también a aquellos neófitos romanos deseosos de querer aprender lo esencial de los «asuntos humanos» a través de los escritos del hombre fracasado en la vida política y militar que fue Salustio. El relato histórico es maestro para la vida del futuro hombre político así como lugar literario privilegiado para mostrar en el desarrollo de la narración lo propio e impropio el hombre.

El antiguo magistrado romano emplea sus últimos años de vida en el otium propio de los señores romanos -ocio alejado de las prácticas licenciosas y burdas propias del hombre depravado-. La escritura histórica pergeñada en la quietud y soledad del Horti Sallustiani -refugio espiritual del antaño hombre público romano- es la actividad a la que debe dedicar su tiempo cualquier admirador de la «antigua» virtud e integridad romana (mos maiorum). Parece innecesario - por ser bien conocido- señalar que la peripecia vital sufrida por Salustio no es la excepción entre los hombres de letras romanos y latinos. Buena parte

1 En este artículo no se hará mención alguna a las Invectivas y Cartas atribuidas al Pseudo-Salustio. Vd. Santos Yanguas, N. (1997, 11).

2 La información sobre la vida de Salustio es escasa. Se conservan pocos testimonios antiguos acerca de su vida. De origen sabino, fue educado en Roma donde frecuentó ámbitos cultos y mostró desde un primer momento inclinaciones austeras. Salustio pertenecía a una familia plebeya y relativamente acomodada carente de relieve o influencia política alguna. Mediante no siempre buenas artes, al igual que Cicerón, supo convertirse en uno de los conocidos en aquel momento como homines novi. Su carrera política lo condujo a convertirse en Tribuno de la Plebe aunque posteriormente fue acusado de adulterio y expulsado del Senado. Se alineó con el bando cesarista en la guerra contra los pompeyanos e hizo uso de su fortuna personal para escribir su obra histórica en su casa de campo u horti Sallustiani. Vd. Santos Yanguas, N. (1997, 7-23).

3 Vd. Los Prólogos de las obras Guerra de Jugurta y Conjuración de Catilina. 
de los historiadores latinos escriben sus obras tras el abandono -y probablemente en buena parte de los casos- como consecuencia de su fracaso en las vicisitudes del cursus honorum (SYME, 1970, 1-11). Es propio tanto de patricios como de los homines novi-personajes como Salustio y Cicerón- dedicar su tiempo a aquello que Séneca en sus diálogos Sobre el ocio y Sobre la brevedad de la vida entendería como el genuino y auténtico disfrute del tiempo del hombre libre divinizado. Tras el abandono de la vida pública, el recuerdo y la reflexión sobre aquellos sucesos vividos o estudiados y juzgados como sucesos de especial relevancia para Roma es el entretenimiento predilecto de aquellos cuerpos romanos acomodados al tiempo que resentidos.

Así, en los escritos de Salustio es posible encontrar tesis de naturaleza antropológica ${ }^{4}$, ética y política ilustradas mediante narraciones con distinto grado de carga histórica o ficcional (WOODMAN, 1988). En los proemios de sus obras monográficas -Conjuración de Catilina y Guerra de Jugurta- podemos rastrear las tesis filosóficas fundamentales defendidas por Salustio, tesis que son posteriormente ejemplificadas mediante sus narraciones históricas. Entre tales tesis esbozadas en los primeras páginas de sus obras y las narraciones y los desarrollos historiográficos posteriores podemos encontrar una concordancia fundamental acerca de lo específico del hombre y de su condición así como acerca de las brechas potenciales del frágil entramado legal e institucional conocido como res publica, es decir, aquellos puntos por los cuales los sistemas políticos suelen encontrar el camino de su propia destrucción.

Por un lado, Salustio selecciona aquellos sucesos capitales de la historia política y militar de Roma que pudieran mostrar los peligros a los que siempre se vería enfrentada la República de Roma y verosímilmente cualquier otro sistema político de naturaleza similar. Por otro lado, el historiador latino conforma retratos de personajes literarios «arquetípicos» e «idealizados» que pudieran ser tomados como referentes de la acción pública y privada de los hombres romanos. Modelos en virtud de su comportamiento máximamente loable o bien en personajes contra-modélicos en virtud de su comportamiento absolutamente reprobable. De tales sucesos, acciones y discursos podrían los jóvenes romanos obtener lecciones provechosas para orientar y ordenar sus vidas públicas y privadas. No son ni el fatum ni la providencia los responsables últimos de los males públicos de los hombres, sino que son sus vicios adquiridos y sus errores los que les impiden afrontar y superar las adversidades de la fortuna.

Las dos obras legadas que han sobrevivido al paso de los tiempos de manera completa y no fragmentaria - La Guerra de Yugurta y La Conjuración de Catilina- narran sucesos de especial relevancia para comprender los peligros siempre latentes que amenazan a la República Romana. Tales peligros son de naturaleza pública y política aunque tienen una etiología de carácter antropológica-moral derivada del desorden afectivo, emocional y pasional producido por individuos movidos e incluso devorados indefectiblemente por sus bajas pasiones. La república equilibrada y gloriosa estuvo en crisis -algo que los jóvenes nunca deben olvidar- ya que tanto los patricios ambiciosos y glotones como la «turba» movida por la imposible tarea de satisfacer sus desmedidos e insatisfechos apetitos corporales -a mala imitación de los hábitos y costumbres de los patricios- no pudieron, no supieron o no qui-

4 Vd. Los Prólogos de las obras Guerra de Jugurta y Conjuración de Catilina. 
sieron evitar que las bajas y tristes pasiones los condujeran en direcciones cuyos desmanes y deudas acabaría pagando la ciudad en su conjunto ${ }^{5}$. Ambos episodios de la historia política de Roma -la corrupción de la nobleza dirigente y las sediciones plebeyas recogidas en los relatos de Salustio- aparecen como dos caras de un mismo proceso de descomposición de la vieja república que tiene lugar en Roma tras el final de las guerras contra los cartagineses (MAS, 2012). Tal parece ser el acontecimiento y punto de inflexión fundamental de la odisea de los mores romanos. Y es el relato de tal proceso de «declive» aquel que puede engalanar con la gloria y la inmortalidad literaria al ya envejecido Salustio.

\section{Personajes principales de las historias de Salustio: modelos de comportamiento, desequilibrio emocional, imprevisibilidad en la acción}

Los personajes principales de los historias de Salustio ejemplifican «tipos humanos» movidos todos ellos por fuerzas y poderes residentes en un fondo vital, emocional, pasional y anímico sin cuya presencia y sin cuyo potencial movilizador efectivo sus acciones serían cabalmente inexplicables (ROSENWEIN, 2002). En tal fondo -en realidad poco conocido por el sujeto agente de la acción aunque más fácilmente reconocible por el observador de ésta- habitan los vástagos de la dimensión irascible y concupiscible del hombre. Éstos son o bien huéspedes pasajeros y mudables o bien elementos constitutivos ya de la propia corporalidad del individuo. Es en este movimiento de fondo y en su «racionalidad objetiva» (M. Weber) donde se activan las causas efectivas fundamentales y no meramente ideológicas, deformantes o propagandísticas, el «no-lugar» - espacio de tránsito y mudanza (M. Augé) - donde se activan sucesos tan poco edificantes para la mirada del moralista latino como son la Guerra de Numidia o la conjura de los «catilinarios». Los sujetos de la historiografía Salustiana son efectivamente movidos por un enredo emocional cuyo entretejimiento parece ser difícil de desentrañar por el paciente de tal enredo. Dificultad que se manifiesta en la frecuente fabricación de pretextos que el sujeto alega para dar rienda suelta a un obrar sustancialmente emocional. Obrar que con frecuencia se reviste de «racionalidad subjetiva» a través de las máscaras y vestidos proporcionados por pretextos variopintos.

Poco hay en el comportamiento de los personajes de las obras de Salustio que nos pueda hacer pensar que son elementos estrictamente racionales -como la planificación, el cálculo o la autodeterminación de la voluntad- los que ponen en marcha sucesos que condicionan y determinan el curso de la vida política de Roma. Por ejemplo, el miedo y la ambición son emociones omnipresentes en la atmósfera literaria genialmente descrita por Salustio. Y también lo son la desconfianza y el deseo irrefrenable de vengar las afrentas y vejaciones sufridas y soportadas. Tales estados de ánimo son los que desequilibran el alma de los personajes salustianos, expulsando a éstos de su estado de quietud y reposo propio de su «vida ordinaria» y alterando así el curso de sus biografías y con éstas el desenvolvimiento de las cosas de Roma. De tales desequilibrios ocasionales surgirán guerras, conjuras y sediciones, sucesos que modificarán el curso del estado de cosas existente en Roma. Las estrictas, rígidas y severas normas de comportamiento asumidas por los

5 Tal parece ser el análisis político contenido en la obra de Salustio. 
ancestros romanos como normas indiscutibles -normas que sirven en muchos casos como mecanismos «civilizatorios» de autorregulación emocional (ELIAS, 1977)- aparecen frecuentemente como armazones «éticos» quebrados, fracturados o simplemente triturados en el escenario posterior a la victoria militar de Roma sobre Cartago. La indicación de la importancia de este episodio como acontecimiento fundamental de la historia de Roma es frecuente en la obra de Salustio:

Por otro lado, se condujo con los mejores principios morales y la más grande concordia entre la segunda y la tercera guerra púnica, (y la razón no fue el amor a la justicia, sino el miedo a una paz poco de fiar mientras estuviese en pie Cartago). Mas la discordia, la codicia, la ambición y demás males que suelen originarse en medio de la prosperidad aumentaron enormemente después de la destrucción de Cartago. Pues las injusticias de los más poderosos y por mor de ellas el alejamiento entre la plebe y los patricios, así como otras disensiones, tuvieron lugar de puertas adentro desde el comienzo, y tras la expulsión de los reyes, hubo un comportamiento conforme a derecho, justo y comprensivo, sólo mientras duró el miedo que inspiraban Tarquinio y la grave guerra con Etruria ${ }^{6}$.

La estricta moralidad romana en la que aún estaban presentes como realmente interiorizados y reconocidos los «mitos de fundación» de la ciudad y la forma de vida coherente con las hazañas realizadas por los héroes romanos regulaba y hacía de alguna manera predecible el comportamiento de los actores romanos. Nada de esto parece ocurrir ya en una Roma en la que los señores -gracias a las rentas que llegan a Roma desde los territorios de la periferia antaño conquistada por los ejércitos romanos-están fuertemente instalados en la molicie. La extracción de rentas llegadas a Roma desde los territorios conquistados hacía innecesaria la observancia de los códigos morales tradicionales (HOPKINS, 1978), códigos caracterizados por el ensalzamiento del trabajo.

Así, el miedo experimentado por el joven y amado por todos sus convecinos Jugurta ante la supuesta conjura ideada por los envidiosos, ambiciosos y pérfidos hermanos- pondrá en marcha los sucesos que obligarán a la clase dirigente romana, ensimismada en los dulces placeres de lo molicie, a involucrarse en el control del Mediterráneo Occidental. O el caso de Catilina, arquetipo en la obra de Salustio de la figura del «demagogo-conspirador» contra la república, aparece como un sujeto cuyas palabras dan cobertura a las ansias de rebelión que padece la plebe sobre-endeuda. Las palabras de Catilina son presentadas por Salustio como el dispositivo retórico que permite a los romanos incapaces de afrontar sus compromisos adquiridos no solo dar solución a su desesperada situación sino también verse a sí mismas como víctimas del reparto de la felicidad en la ciudad de Roma ${ }^{7}$. O los senadores romanos aparecen como hombres incapaces de actuar de manera distinta a aquella que dicta su apetito. O los generales romanos como Bestia -encarnación de la avaricia- o Albino -máximo representante de la incompetencia- o Metelo, cuya arrogancia infinita hace inviable cualquier

6 SALUSTIO (Hist. I 11).

7 La mirada de Salustio en este punto no es precisamente comprensiva respecto de las condiciones de vida de aquellos que se ven obligados a endeudarse para sobrevivir. 
solución a la discordia militar y política. Figuras todas ellas retratadas de manera perspicaz y detallada por Salustio. El dictador Sila, por ejemplo, aparece retratado así:

De modo que Sila era noble, de linaje patricio, aunque su familia casi había caído en el olvido por la indolencia de sus mayores; instruido por igual en la literatura griega y latina, era de gran ánimo, y estaba ansioso de placeres y más aún de gloria; cuando no tenía nada que hacer era un disoluto, aunque el placer nunca lo apartó de sus actividades [...] Era fácil de palabra, astuto y sencillo en la amistad; poseía una increíble profundidad de espíritu para fingir o disimular sus asuntos y era pródigo en muchas cosas, y especialmente con el dinero [...] y más bien se esforzaba por que hubiese muchos que le debiesen; intercambiaba bromas y veras con los más humildes; prestaba su asistencia sin cansancio en las obras, en la marcha y en las guardias, y, a esto, no hacía lo que suele hacer la maldita ambición, a saber, dañar la reputación del cónsul o de cualquier otra persona honrada, únicamente no consentía que hubiera otro superior a él en el consejo o en la acción, y a la mayoría los aventajaba. ${ }^{8}$

El éthos colectivo descrito en los relatos de Salustio -se dedica especial atención a los personajes romanos aunque también a algunos protagonistas númidas- es en ocasiones desafiado por las heroicas acciones de los esforzados, rectos y auto-contenidos homines novi -mutatis mutandis se podría decir hoy «hombres hechos a sí mismos»- grupo social alejado de los excesos de los patricios acomodados y degenerados por la molicie así como de los plebeyos depauperados por la mala imitación de la vida propia de romanos acaudalados. Tal es el grupo social loado y encumbrado por los escritos de Salustio y tal es el éthos de grupo que aún podría servir como referencia vital y moral a los jóvenes romanos. Personajes todos ellos en los que no deja de estar presente ese fondo emocional pero que es de alguna manera regulado y controlado por su carácter sublimado por una inteligencia de carácter no estrictamente instrumental y cuyas pasiones están redirigidas hacia otros fines compatibles con la existencia del bien público, fines como son el deseo de honra presente y de gloria futura.

Figuras que sin haber heredado de cuna la dignitas de los patricios romanos son individuos cuyo mérito, valentía e integridad hacen de ellos los únicos capaces de seguir los pasos de los ancestros fundadores de Roma. Figuras como la de Mario, ejemplo paradigmático del individuo íntegro que es movido por un deseo de gloria -recuerdo de sus descendientes, reconocimiento intergeneracional- lo suficientemente potente como para domeñar las fuerzas y poderes del bajo cuerpo. Seres divinizados en un tiempo en el que el hombre ha olvidado y ha dejado de tener contacto con lo heroico e incluso con lo divino que en él habita.

\section{La «fragilidad» de la res publica: sedición y faccionalismo}

Los relatos de Salustio rezuman una fuerte carga valorativa de naturaleza nostálgica a través de los cuales es posible identificar la valoración moral y política que el autor mantiene respecto de su tiempo. En sus escritos se reconoce la valoración positiva de las mores maiorum -rígidas costumbres y normas de los ancestros fundadores que hicieron de

8 SALUSTIO (Jug. 95-96). 
Roma una ciudad grande en dignidad e integridad- al tiempo que se reprueba el comportamiento de buena parte de los romanos coetáneos del escritor latino. Los antiguos romanos ansiaban ganar el buen nombre, la gloria y con ellos la inmortalidad que proporciona la memoria colectiva. De tener voz los antiguos seguramente hubiesen defendido la siguiente máxima: sin bellas y nobles acciones guiadas por la probidad y por la integridad no es posible ganar la batalla al transcurrir del tiempo y a los efectos causados por el olvido.

Sin embargo, los contemporáneos de Salustio -aquellos que habían expulsado a Salustio de la vida pública y del cursus honorum - habían olvidado la verdad de tal máxima y habían abrazado un nuevo dios que los exhortaba a la búsqueda de cargos públicos que les permitieran ganar influencia en la vida política y económica de la ciudad. Actividades poco propias de hombres que buscan hacerse un hueco en el panteón de los hombres ilustres que recoge la memoria de la ciudad. Hombres del presente olvidadizos de aquello que hizo grande a su ciudad y renuentes a sacrificar su visibilidad y comodidad presente por mor de un posible pero incierto reconocimiento de la posteridad.

Bajo tales condiciones y con la existencia de tales hombres parecía improbable que la res publica pudiera perdurar en el tiempo. La existencia de las res publica requiere de hombres auto-disciplinados y auto-contenidos que prefieran la gloria intemporal al poder y a la influencia transitoria. Los límites de la res publica y de la política son claros y exigentes: ambas son bellas y delicadas flores que deben ser cultivadas individual y colectivamente. En su ausencia aparece la tiranía o la oligarquía y, como consecuencia poco menos que necesaria de la existencia del gobierno oligárquico, aparece también su contrapunto, a saber, la demagogia o el populismo.

La mirada de Salustio sobre su tiempo es la mirada propia del hombre libre cultivado reacio a perder su condición social y reacio también a la transformación radical del estado de cosas existente. Hombre libre que reconoce las obligaciones a las que deben hacer frente las élites políticas y económicas así como defensor de la necesidad de la existencia de un espacio en la república para aquellos individuos o grupos sociales que no forman parte de las élites. En la figura del homo novus -miembro de una familia anteriormente excluida de la vida pública que por vez primera vez entra a formar parte del senado- es posible reconocer el hombre en el que la memoria, la subjetividad y una mirada plebeya aún no completamente sepultada por el fácil imperium desdeñoso del imperativo de la legitimidad y por el deseo de goces infinitos del oligarca que ha perdido definitivamente el contacto con cualquier forma de vida que no sea la que él mismo frecuenta. Tal homo novus no puede dejar de despreciar al homo embrutecido, hombre que siempre querrá expulsar al novus del senado 9 . Hombre embrutecido al que el hombre cultivado no puede aceptar como compañero de andanzas y aventuras políticas. En este punto, los afectos de las élites políticas y sociales se distancian entre sí más allá de la posible confluencia de intereses materiales compartidos.

Por medio de sus escritos Salustio advierte a sus lectores de la siempre posible descomposición y putrefacción de la res publica y, por tanto, de la facilidad con la que los intereses facciosos, individuales, y estrictamente privados dan al traste con los más excelsos intentos de que el bien común prime sobre cualesquiera otros intereses. La posibilidad de la res

9 Vd. SEGURA RAMOS, B. (7-59) 
publica descansa sobre un material humano mudable, irascible y propenso al autoengaño. Tal inestabilidad característica de los ánimos y humores de los hombres es motivo fundamental de la fragilidad propia de la esfera pública.

\section{Referencias bibliográficas}

Elias, Norbert (1977): El proceso de la civilización, Fondo de Cultura Económica, México D. F.

Hopkins, Keith (1978): Conquistadores y esclavos, Península, Barcelona. Traducción de Marco-Aurelio Galmarini.

Mas, Salvador (2012): "Salustio, las tareas del historiador", en Vivir para pensar, Gómez Ramos, A. y Roldán, C. (Eds.), Herder, Barcelona.

Rosenwein, Barbara (2002): "Worrying about emotions in history", The American Historical Review Vol. 107, Issue 3.

Salustio: Conjuración de Catilina. Guerra de Jugurta. Fragmentos de las «Historias», Biblioteca Clásica Gredos, Madrid. Introducción, traducción y notas de Bartolomé Segura Ramos.

Santos Yanguas, Narciso (1997): La concepción de la historia en Salustio, Servicio de Publicaciones de la Universidad de Oviedo.

Segura Ramos, Bartolomé (1997): Introducción general”, en la edición de Salustio de la Biblioteca Clásica Gredos.

Syme, Ronald (1970): Ten Studies in Tacitus, Clarendon Press, Oxford.

Woodman, A. J. (1988): Rhetoric in Classical Historiography. Four studies, Areopagitica Press, Portland. 